\title{
EDUCAÇÃO ESPECIAL NO BRASIL: DESIGUALDADES E DESAFIOS NO RECONHECIMENTO DA DIVERSIDADE
}

\author{
Mônica CARVAlHo MagalHães KaSSAR
}

\begin{abstract}
RESUMO: Abordar a educação especial no Brasil implica considerar a política educacional proposta nos últimos anos pelo governo federal e, especialmente, a presença nas escolas de diversas populações, que constituem o país de formas historicamente desiguais. A partir dessas considerações, este artigo propõe-se, inicialmente, a analisar mudanças registradas na educação das populações marginalizadas do processo escolar, especialmente de pessoas com deficiências e, posteriormente, contribuir com reflexões sobre limites ainda presentes na educação brasileira, incluindo as complexas relações que envolvem os lugares da diferença nas proposições legais e nas práticas escolares.
\end{abstract}

Palavras-chave: Educação brasileira. Educação especial. Educação inclusiva. Escolaridade de alunos com deficiências.

\section{Special education in Brazil: inequalities AND ChallengeS IN THE RECOGNITION OF DIVERSITY}

ABSTRACT: Addressing Special Education in Brazil implies considering the educational policy proposed by the Federal Government in recent years and, especially, the presence of various populations in schools, who constitutes the country in historically unequal ways. Based on these considerations, the article proposes to analyze changes observed in the education of populations that are marginalized from the school process, especially people with disabilities, and afterwards to contribute with reflections about the limits that are still present in Brazilian education, including the complex relationships involving the role of the difference in legal propositions and school practices.

Key words: Brazilian education. Special education. Inclusive education. Education of students with disabilities.

* $\quad$ Doutora em Educação e professora associada do Departamento de Educação da Universidade Federal de Mato Grosso do Sul (UFMS). E-mail: mkassar@terra.com.br 


\title{
L'ÉDUCATION SPÉCIALE AU BRÉSIL: LES DÉFIS ET LES INÉGALITÉS DANS LA RECONNAISSANCE DE LA DIVERSITÉ
}

\begin{abstract}
RÉSUMÉ: L'approche de l'éducation spéciale au Brésil implique l'examen de la politique éducative proposée ces dernières années par le gouvernement fédéral et, spécialement, la présence de populations diverses dans les écoles, qui constituent le pays de manières historiquement inégales. À partir de ces considérations, cet article propose, initialement, d'étudier les changements rapportés dans l'éducation des populations marginalisées du processus de l'école, en particulier les personnes handicapées, et par la suite, de contribuer à la réflexion sur les limites toujours présentes dans l'éducation au Brésil, et les relations complexes impliquant les lieux de la différence dans les propositions juridiques et les pratiques scolaires.

Mots-clés: Éducation brésilienne. L'éducation spéciale. L'éducation intégratrice. L'éducation des élèves handicapés.
\end{abstract}

\section{Introdução}

$\mathrm{N}$ Silva, 1928)

O trecho anterior, escrito por Pacheco e Silva, médico responsável pelo hospital Juquery entre 1924 e 1937, refere-se às condições inadequadas de atendimento às crianças internas no "Pavilhão de Menores" daquela instituição e integra uma carta endereçada ao Dr. Norberto Sousa Pinto e publicada em 1928 na apresentação da obra $A$ infância retardatária, de Sousa Pinto. O trecho expressa uma preocupação relativa ao atendimento educacional a crianças que, na época, eram consideradas anormais. Do início do século XX ao início do século XXI, o que mudou em relação à educação dessas pessoas? "Traduzir" os termos da época para os de hoje poderia nos auxiliar a afirmar a atualidade das preocupações expostas? Hoje poderíamos dizer: "Temos um grupo de crianças com deficiência intelectual. No entanto, até hoje não conseguimos dar-lhes o necessário desenvolvimento, em virtude das dificuldades em se conseguir professores especializados". Estaríamos hoje diante dos mesmos problemas? A partir desta pergunta, apresento os objetivos deste artigo que pretende, inicialmente, analisar mudanças registradas na educação das populações marginalizadas do processo escolar, em especial de pessoas com deficiências e, posteriormente, contribuir com reflexões sobre limites ainda presentes na educação brasileira, incluindo as complexas relações que envolvem os lugares da diferença nas proposições legais e nas práticas escolares. 


\section{Avanços e limites das políticas educacionais para alunos com defi- ciências}

Falar sobre a educação especial no Brasil implica, necessariamente, a consideração de dois aspectos constitutivos de nossa história: a desigualdade e a diversidade. O país é construído a partir da diversidade de populações e de suas histórias, mas de forma extremamente desigual. A formação econômica do Brasil e as características de sua organização social fizeram com que o país passasse a conviver com vários problemas que impactaram diretamente a vida de crianças e jovens brasileiros, muitos dos quais presentes até hoje: crianças abandonadas nas ruas das grandes cidades, desde o século XVII (Lima \& Venâncio, 1991), restrita cobertura escolar e, consequentemente, um número grande de analfabetos (Gomes, 2001; Lima, 2011), entre outros. Findado o regime escravocrata, muitas famílias não foram incorporadas diretamente ao setor produtivo, passando a sobreviver nas grandes cidades, sem acesso a condições de vida minimamente satisfatórias. Na República, a massa de brasileiros desempregada e considerada iletrada foi identificada como marginal e seus hábitos vistos como indecentes e de transgressão aos bons costumes, aos olhos de uma elite que tomava seu país como atrasado em relação à Europa. Nesse período, parte dos países europeus já havia universalizado o ensino obrigatório, o que levou Hobsbawn (1989) a denominar de "era da escola primária" o período entre 1870 e 1914.

A visão de marginalidade foi direcionada tanto aos adultos das camadas pobres quanto a seus filhos. Para não pertencer a esse grupo, a criança deveria estar enquadrada em requisitos de convivência social, que envolviam aspectos como: vestimenta adequada, boa higiene, bons modos e boa aparência. Os que não se encaixavam muitas vezes eram focos de ações coercitivas e policiais (Lodoño, 1991).

No conjunto de crianças marginais encontravam-se também crianças com deficiências. Um estudo encomendado pelo diretor geral da Instrução Pública do estado de São Paulo em 1913, levado a cabo por Carneiro Junior, evidencia esse aspecto ao orientar a identificação de alunos anormais nas escolas públicas:

Si entramos em um grupo escolar, sobretudo em um daquelles que funccionam em regiões pobres, encontraremos entre as creanças que o frequentam, algumas de talhe rachitico, de compleição assymetrica, - de crescimento irregular, de craneo mal conformado, - de desenvolvimento intellectual irregular, - de sentimentos moares pervertidos. (...). Outras têm o olhar vago, opaco, amortecido, sem vida, sem fixidez e sem brilho. (Carneiro Junior, 1913, p. 18-19; grifos nossos)

A tênue distinção entre marginalidade, pobreza e deficiência também pode ser identificada no decreto que instituiu o Código da Educação do estado de São 
Paulo em 1933. Como parte da educação especializada, além de escolas específicas para crianças com deficiências, também estavam previstas escolas "de educação emendativa dos delinquentes" (Decreto n. 5.884, de 21 de abril de 1933, art. 794). Para uma educação eficiente, as crianças deveriam ser separadas a partir de suas características. Baseados na aplicação dos estudos ${ }^{1}$ de Alfred Binet (1857-1911) e Theodore Simon (1872-1961), os serviços de higiene dos diferentes estados brasileiros passaram a classificar os alunos entre normais e anormais, iniciando um processo de "patologização" escolar, ao adotar uma visão psicopedagógica no atendimento aos alunos com deficiências (Jannuzzi, 1985, 2004). O olhar para a diferença indicava a separação, procedimento adotado em diferentes estados brasileiros. ${ }^{2}$

Em relação à educação pública geral, Silva e Schelbauer (2007) lembram que tal período da história brasileira "marca a preocupação com a alfabetização da miscigenada população brasileira, no qual não bastava instruir, era necessário educar" (p. 123), pois a educação era vista como antídoto à marginalidade e ao atraso do país. Esse aspecto está registrado no Manifesto dos Pioneiros da Educação Nova, de 1932:

\footnotetext{
Na hierarquia dos problemas nacionais, nenhum sobreleva em importância e gravidade ao da educação. Nem mesmo os de caráter econômico lhe podem disputar a primazia nos planos de reconstrução nacional. Pois, se a evolução orgânica do sistema cultural de um país depende de suas condições econômicas, é impossível desenvolver as forças econômicas ou de produção, sem o preparo intensivo das forças culturais e o desenvolvimento das aptidões à invenção e à iniciativa que são os fatores fundamentais do acréscimo de riqueza de uma sociedade. (Manifesto, 1932)
}

Ao longo de todo o século $\mathrm{XX}$, as estatísticas brasileiras foram registrando paulatinamente a ampliação do atendimento educacional no país, tanto no que se refere ao número de alunos matriculados, quanto ao tempo de escolarização (Gomes, 2001; Lima, 2011). Apesar de esforços empreendidos nos diferentes governos no decorrer do período, apenas na década de 1990 o país alcançou taxas de matrícula no ensino obrigatório próximas à universalização. Entre as populações atendidas no processo de universalização da escolaridade obrigatória, encontram-se aquelas que historicamente foram dela excluídas, inclusive a que hoje é foco da educação especial, em salas de aulas de escolas públicas, em classes especiais, em escolas ou instituições especializadas públicas ou privadas (Jesus \& Vieira, 2011). Em relação às características dessa população, o conceito de necessidades educacionais especiais, adotado no país até a divulgação da Política Nacional de Educação Especial na perspectiva da educação inclusiva, em 2008, ainda lançava - de certa forma -um olhar pouco nítido sobre o aluno da educação especial. A utilização desse conceito, embora tivesse como intenção declarada ressaltar a necessidade de adaptação dos processos educativos a qualquer indivíduo (que apresentasse dificuldades por 
tempo limitado ou não), muitas vezes contribuiu para a continuidade da "patologização" de parcelas da população, especialmente das camadas mais pobres, como foi frequente na história da educação brasileira (Collares \& Moyses, 1994; Gomes, 2009).

Atualmente, muitos alunos com deficiências, transtornos globais do desenvolvimento e altas habilidades/superdotação estão matriculados em classes comuns de escolas públicas em todo território nacional, o que denota uma mudança de perspectiva em relação a essa população: da crença anterior de que o atendimento ideal deveria ocorrer em locais específicos, separadamente ao destinado à população em geral, para a atual percepção de que os espaços mais adequados são os espaços comuns. Para fortalecer essa perspectiva, a legislação brasileira vigente estabelece a não exclusão do aluno do sistema educacional geral sob alegação de deficiência, privilegia a matrícula desses alunos em escolas comuns públicas e, para apoio educacional, investe na implantação de salas de recursos multifuncionais em todo o país, de modo que, entre 2005 e 2011, foram disponibilizadas 37.801 salas de recursos multifuncionais em 5.019 municípios (Rebelo, 2012).

\section{Contribuições para mudanças de concepção}

A partir da Declaração Universal dos Direitos Humanos de 1948, formulada após a Segunda Guerra Mundial, a preocupação com a não discriminação passa a ser ressaltada, inclusive a discriminação na educação, como atesta a Convenção de 1960 (Convention against Discrimination in Education), adotada pelo Brasil em 1968:

Para os fins da presente Convenção, o termo "discriminação" abarca qualquer distinção, exclusão, limitação ou preferência que, por motivo de raça, cor, sexo, língua, religião, opinião pública ou qualquer outra opinião, origem nacional ou social, condição econômica ou nascimento, tenha por objeto ou efeito destruir ou alterar a igualdade de tratamento em matéria de ensino, e, principalmente:

a) privar qualquer pessoa ou grupo de pessoas do acesso aos diversos tipos ou graus de ensino;

b) limitar a nível inferior a educação de qualquer pessoa ou grupo;

c) (...) instituir ou manter sistemas ou estabelecimentos de ensino separados para pessoas ou grupos de pessoas; ou

d) impor a qualquer pessoa ou grupo de pessoas condições incompatíveis com a dignidade do homem.

Situações vividas em decorrência da Segunda Guerra contribuíram para a formalização dos direitos sociais e humanos e também impactaram a percepção das formas de atendimento das pessoas com deficiências. Em 1969, foi publicada a coletânea Changing patterns in residential services for mentally retarded, organizada por 
Robert Kugel e Wolf Wolfensberger, composta de estudos de pesquisadores de vários países, que criticavam o confinamento asilar de pessoas com deficiências. Entre os capítulos, estava o escrito pelo sueco Bengt Nirje (Flynn \& Lemay, 2008), em que apresentava formalmente o conceito de normalização. Na comemoração dos 25 anos de publicação desses estudos, Nirje, em conferência realizada em 1994, explicitou a relação entre a elaboração do conceito de normalização e suas experiências vividas durante a guerra. $\mathrm{O}$ autor, que visitou campos de refugiados como colaborador da Cruz Vermelha, conheceu naqueles locais pessoas que, em princípio, eram saudáveis e a partir da experiência de confinamento passaram a apresentar comportamentos patológicos. Outro capítulo a ser ressaltado é do dinamarquês Neils Erik Bank-Mikkelsen, que, ao ser preso em campo de concentração nazista, deu-se conta de que o tratamento destinado a pessoas com deficiências nos asilos era muito próximo ao que ele foi submetido na guerra. ${ }^{3}$ Ambos os estudiosos perceberam que a situação de segregação levava necessariamente à formação de uma vida alienada ao cotidiano das pessoas não institucionalizadas, com padrões de comportamentos reforçados pela própria vida institucional. ${ }^{4}$ Os autores ponderaram que, se os impactos da institucionalização são extremamente prejudiciais a pessoas que, em princípio, não possuem diferenças orgânicas que dificultem sua apropriação de conhecimentos em seu mundo circundante, o malefício às pessoas com deficiências certamente seria muito pior.

A partir dessas vivências, no início dos anos de 1960, Nirje formalizou, em suas publicações, direitos fundamentais que deveriam ser respeitados no trato com pessoas com deficiências. Segundo o autor, todas as pessoas com deficiências teriam o direito de vivenciar: experiências normais do ciclo da vida; o respeito e direito à sua autodeterminação; uma vida sexual normal para os padrões pertinentes à sua cultura; vivenciar o envolvimento em atividades econômicas comuns à sua sociedade; possuir diretos sociais; e compartilhar um ambiente normal relativo aos padrões e regras aceitos em sua comunidade (Nirje, 2008). Essa perspectiva foi incorporada pela legislação daqueles países (Suécia e Dinamarca) e por acordos formulados pela Organização das Nações Unidas (ONU).

A partir de então, vários países, inclusive o Brasil, passaram a adotar propostas menos segregadas para a educação de pessoas com deficiências e a modificar suas leis para a garantia de direitos a essa população, de forma ampla. Essa atmosfera contribuiu para que movimentos internos da sociedade civil brasileira encontrassem eco em suas reivindicações, como na organização do Conselho Brasileiro de Bem-Estar do Cego, na formação da Associação dos Pais e Amigos dos Excepcionais (Apae), ambos em 1954, entre outros (Jannuzzi, 1985; 2004), e na aprovação do Artigo 88 da primeira Lei de Diretrizes e Bases da Educação Nacional, em 1961, que previa a matrícula dos excepcionais, ${ }^{5}$ quando possível, enquadrada "no sistema geral de educação, a fim de integrá-los na comunidade" (Brasil, 1961). 
Atualmente, diferentes autores desenvolvem pesquisas ressaltando benefícios para a vida das pessoas com deficiências que participam de instituições sociais em geral (não segregadas). Em relação à educação, Downing e MacFarland (2010) apresentam trabalhos que comparam o desenvolvimento de alunos em situação de escolaridade comum e em situação de escolaridade com convívio apenas de outras crianças com deficiências em diferentes países:

\begin{abstract}
Em estudo comparativo desenvolvido na Holanda, Peetsma et al. (2001) descobriram que, após um período entre dois e quarto anos, estudantes com deficiências tiveram mais progressos no uso da linguagem e nas operações matemáticas em escolas comuns quando comparadas com escolas especiais. Outro estudo comparativo, de Foreman et al. (2004), demonstrou que estudantes com deficiências profundas nas escolas australianas tiveram mais interações comunicativas em situações de inclusão quando comparados com seus colegas em classes especiais segregadas. Nos Estados Unidos, Fisher e Meyer (2002) demonstraram as aquisições (benefícios) da inclusão em relação às situações de educação segregada para estudantes com deficiências múltiplas e severas na comunicação, no desenvolvimento de habilidades sociais ao longo de um período de dois anos. (Downing \& MacFarland, 2010, p. 3)
\end{abstract}

Vemos que em todas as situações apresentadas, alunos que estudam junto a outros em situações comuns adquirem um desenvolvimento mais adequado. Os autores enfatizam que isso ocorre mesmo com crianças com deficiências severas.

A adoção desses princípios vem sendo fortemente defendida por organismos internacionais ligados à Organização das Nações Unidas. Um relatório elaborado pela Organização Mundial da Saúde (OMS), com apoio do Banco Mundial, em 2011, sobre o atendimento às pessoas com deficiências em diferentes países afirma que deve ser prioridade nos diferentes países assegurar que as crianças com deficiências recebam boa educação em ambiente inclusivo e lembra que a Convenção das Nações Unidas sobre os Direitos das Pessoas com Deficiências reconhece o direito de todas as crianças com deficiências tanto serem incluídas no sistema geral de educação quanto terem suas necessidades específicas atendidas, inclusive individualmente, quando necessário (WHO, 2011). O documento também adverte que os países signatários não podem deixar de cumprir essas responsabilidades.

Essa visão também tem influenciado fortemente a legislação brasileira e as proposições de escolaridade a essa população, de tal modo que os documentos oriundos do governo federal nos últimos anos anunciam a decisão de implantar o que é denominado de sistema educacional inclusivo. Esse movimento aponta a disseminação de uma perspectiva bastante diferente para o atendimento a alunos com deficiências em relação às proposições adotadas no início do século XX, cujo enfoque primordial era a separação desses alunos.

No entanto, cabe registrar outro lado da questão. Na história recente de atendimento educacional a alunos com deficiências, houve um movimento de fechamento 
de espaços públicos - as classes especiais e oficinas pedagógicas -, por serem considerados espaços de exclusão educacional e social. As classes especiais públicas foram implantadas, em sua maioria, dentro de escolas estaduais durante o século XX. Após a criação do Centro Nacional de Educação Especial (Cenesp), em 1973, houve a disseminação dessas classes por todo o território nacional com o objetivo de cumprir as metas de integração, normalização e interiorização daquele órgão (Ferreira, 1993; Jannuzzi, 1985, 2004). Nesse período também foram instaladas oficinas pedagógicas, para cumprir o papel de formação para o trabalho dessa população, dentro da perspectiva adotada naquele momento, com bases na Teoria do Capital Humano (Jannuzzi, 2004). Nos anos posteriores (do final dos anos de 1970 até os anos de 1990), esses espaços foram alvo de críticas, por serem identificados como espaços de exclusão escolar, já que muitos alunos lá ficavam matriculados sem sucesso escolar por muitos anos (Almeida, 1984; Ferreira, 1993; Paschoalick, 1981; Schneider, 1977). A decorrência desse movimento de crítica, nos anos de 1990, não foi uma possível reconfiguração desses espaços públicos, mas seu fechamento. Dessa forma, a partir de meados da década de 1990, o país passou a possuir poucos espaços públicos de atendimento escolar aos alunos com deficiências.

O fechamento desses espaços públicos coincide com três movimentos importantes. O primeiro refere-se à disseminação do discurso de inclusão escolar e a identificação das matrículas unicamente em espaços especializados como atitudes discriminatórias. Essa perspectiva fica evidente no Ofício n. 184/2001-ZS/PRDF, de 2 de outubro de 2001, oriundo da Procuradoria da República do Distrito Federal, encaminhado ao ministro de Estado da Educação da época, e em outro documento, de 2003, da Secretaria dos Ofícios de Tutela Coletiva de São Paulo. De modo geral, esses documentos pediam revisão do Parecer CNE/CEB n. 17/2001 e da Resolução CNE/ CEB n. 02/2001, pois entendiam que tanto o Parecer quanto a Resolução desrespeitariam o ordenamento jurídico vigente (Convenção Interamericana para a Eliminação de Todas as Formas de Discriminação Contra as Pessoas Portadoras de Deficiência, aprovada pelo Congresso Nacional, em 2001), ao aceitarem extraordinariamente o funcionamento de classes e escolas especiais.

O segundo aspecto refere-se ao processo de municipalização do atendimento ao ensino obrigatório (ensino fundamental), ocorrido a partir da Constituição Federal de 1988, quando muitos municípios passaram a assumir o oferecimento da educação infantil e do ensino fundamental, muitas vezes não prevendo espaços públicos para atendimento educacional aos alunos com deficiências, visto que esses espaços estavam historicamente ligados às escolas estaduais (classes especiais e oficinas pedagógicas).

Ressalta-se que, a despeito de preocupações com processos discriminatórios, escolas especializadas são serviços que demandam recursos volumosos por parte 
dos cofres públicos. Este aspecto é reconhecido em diferentes documentos orientadores da Organização das Nações Unidas para Educação, Ciência e Cultura (Unesco) para atendimento a pessoas com deficiências e consiste em uma das justificativas para que a matrícula de alunos com deficiências em escolas comuns seja adotada como prioridade nos chamados "países em desenvolvimento". ${ }^{6}$ Esta questão nos leva ao terceiro aspecto: a década de 1990 foi marcada, no Brasil, por um incentivo à participação das instituições privadas nas ações sociais, principalmente após a reforma de aparelho de Estado, implantada no Governo de Fernando Henrique Cardoso, em 1995, e com a instituição do marco legal do Terceiro Setor. ${ }^{7}$ A conjugação desses aspectos possibilita o entendimento do recuo do poder público em relação aos serviços de atendimento especializado às pessoas com deficiências.

A partir do Governo de Luiz Inácio Lula da Silva, o Ministério da Educação tem implantado um conjunto de programas e ações para formação da política de educação inclusiva. São ações com esse propósito: Programa Nacional de Formação Continuada de Professores na Educação Especial e Formação de Professores para o Atendimento Educacional Especializado; Programa de Implantação de Salas de Recursos Multifuncionais; Escola Acessível, que visa à adaptação arquitetônica das escolas; Programa Educação Inclusiva: Direito à Diversidade, de formação de multiplicadores para a transformação de sistemas educacionais comuns em sistemas inclusivos; Programa Incluir, para acesso às instituições federais de ensino superior aos alunos com deficiências. Apesar de apresentados como programas separados, essas ações formam um conjunto articulado de proposições que atingem diferentes regiões do país. Esse conjunto de ações sustenta a política de matrícula de crianças com deficiências em massa nas escolas comuns, disseminando a ideia de que qualquer atendimento educacional que substitua a escolaridade em uma escola comum seja uma atitude discriminatória e estaria, portanto, em choque com a Convenção Interamericana para a Eliminação de Todas as Formas de Discriminação Contra as Pessoas Portadoras de Deficiência.

No entanto, cabe notar que, apesar da adoção dessa e de outras convenções que asseguram o direito das pessoas com deficiências à educação (e a todos os espaços sociais), muitos países mantêm diferentes formas de atendimento, como pode ser observado na figura a seguir, retirada do relatório da Organização Mundial de Saúde (OMS [WHO], 2011). A figura 1, na página seguinte, mostra que países como Áustria, Bélgica, República Checa, Inglaterra, Alemanha, Dinamarca, Estônia, Finlândia, França, Holanda, Polônia, Suíça, entre outros, possuem mais de 40\% do atendimento a essa população em escolas ou classes especiais.

Pode-se depreender que há diferentes formas de se interpretar o que se constitui discriminação, ao se propor atendimento às diferentes especificidades humanas. 


\section{Figura 1}

Oferta de educação por tipo/modelo em alguns países Europeus

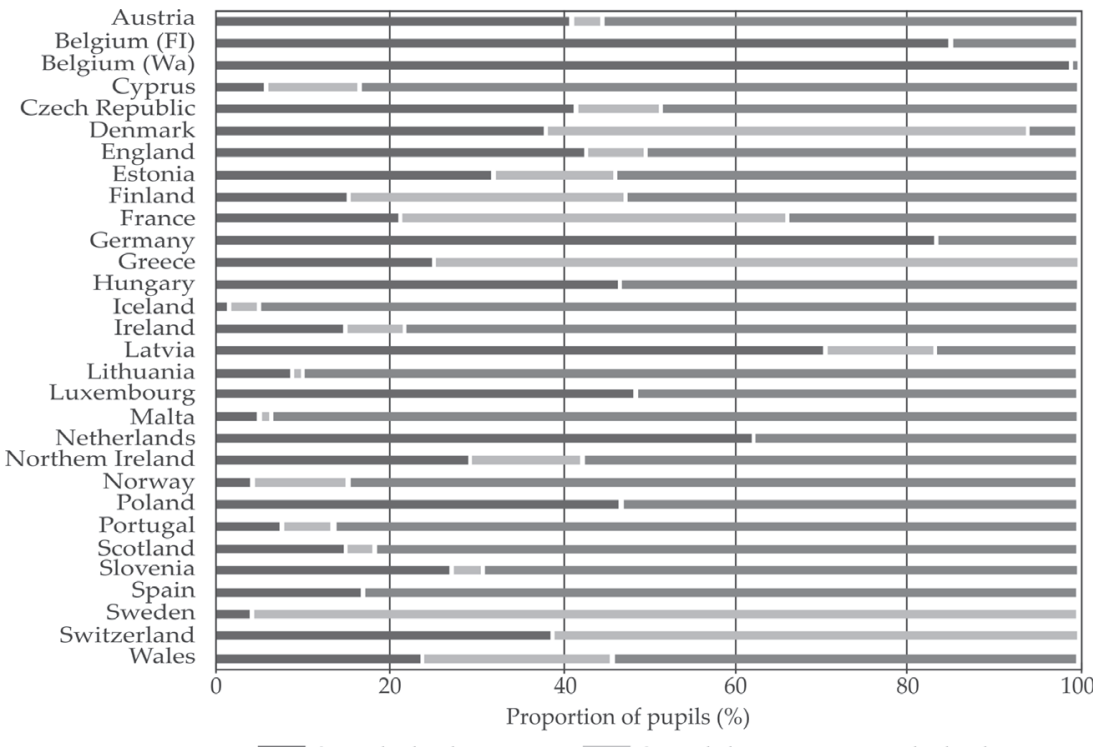

\section{Complexas relações que envolvem o lugar da diferença nas proposi- ções legais e nas práticas escolares}

Pinto e Alves (2010, p. 211) argumentam que “a previsão em lei do ensino obrigatório para uma parcela da população durante um período determinado da infância e juventude tem sido uma das estratégias adotadas por diversos países para viabilizar o exercício do direito à educação a todos os segmentos da sociedade". Em nosso país, há vários instrumentos legais que induzem ao cumprimento deste compromisso. No entanto, como esses mesmos autores reconhecem, essas ações ainda não foram suficientes para se garantir o acesso universal e permanência até o final do ensino fundamental de uma parcela considerável da população.

O "Plano Decenal de Educação para Todos - estratégias para a universalização da educação fundamental e erradicação do analfabetismo no Brasil", elaborado em 1993, apresentava como objetivo, à época, "assegurar, até o ano de 2000, a crianças, jovens e adultos, conteúdos mínimos de aprendizagem" para atender as "necessidades elementares da vida contemporânea" (Brasil, 1993, p. 13). Ao completar quase 20 anos da divulgação do Plano, temos ainda muitos desafios que atestam a 
difícil superação das desigualdades na sociedade brasileira. Pinto e Alves (2010) nos fornecem informações a esse respeito, quando analisam a ampliação da obrigatoriedade da educação básica. Os autores mostram que a taxa brasileira de escolaridade no ensino médio encontra-se muito abaixo das taxas encontradas em países de economia central. Enquanto nesses países a porcentagem da população entre 25 e 34 anos que conclui o ensino médio é de $80 \%$, no Brasil é de $50 \% .{ }^{8}$ No entanto, os dados gerais nacionais encobrem uma desigualdade no país: quando as taxas são analisadas separadamente entre os $20 \%$ da população mais rica e os $20 \%$ da população mais pobre, vemos que $85 \%$ dos jovens pertences às famílias mais ricas concluem o ensino médio, ao passo que, para a população dos $20 \%$ mais pobres, a taxa é de apenas $15 \%$ (Pinto \& Alves, 2010). Esses números trazem à tona não apenas as disparidades sociais, mas também a qualidade da educação oferecida desigualmente às diferentes camadas da população brasileira.

A situação de desigualdade que sustenta esses dados também atinge diretamente as pessoas com deficiências. Na última década, diferentes trabalhos (Gonçalves, 2008; Kassar, 2006; Pletsch, 2010) apontam para situações de fracasso de alunos com deficiências nas escolas comuns, inclusive quando todos os quesitos previstos pela legislação educacional estão presentes (professores formados, salas adaptadas, número de alunos reduzidos por sala, frequência em salas de recursos multifuncionais no contraturno escolar, entre outros). Os resultados encontrados em pesquisas brasileiras parecem discrepar dos resultados de pesquisas em outros países de economia central, como as relatadas por Downing e MacFarland (2010). No entanto, uma análise que enfoque a escolaridade das crianças com deficiências em contraste com a educação geral brasileira nos permite dizer que aqueles alunos não são os únicos a não demonstrar bom desempenho escolar. Expandindo nosso foco para o ensino fundamental brasileiro, é possível identificar vários problemas. Inicialmente, pode-se apontar sua ineficiência em relação a matricular - de fato - toda a população. Lima (2011) explica que, desde a década de 1990, apesar do ensino fundamental brasileiro apresentar condições físicas (capacidade instalada) para atender a todos os indivíduos na faixa etária adequada (número de escolas suficientes), dado o considerável número de indivíduos fora da faixa etária na escola (distorção idade $\mathrm{x}$ série) e de indivíduos em idade própria fora dela, ainda não cumpriu esta obrigação. As análises de Pinto e Alves (2010) também contribuem para entender a dinâmica presente em nossas escolas. Além dos problemas apontados por Lima (2011), temos baixo investimento de recursos em educação pública, quando comparamos recursos do Fundo de Manutenção e Desenvolvimento da Educação Básica e de Valorização dos Profissionais da Educação (Fundeb) de diferentes estados e o investimento em educação pública de países de economia central e mesmo de escolas de elite do estado de São Paulo. 


\section{Considerações finais}

O trecho de Pacheco e Silvia, datado de 1928, traz várias questões: uma explícita e outras implícitas. A questão que está explicitamente apresentada refere-se à dificuldade de se conseguir professores com formação adequada que, de fato, contribuam para uma educação adequada de crianças com deficiências. Nesse sentido, a queixa de Pacheco e Silva parece-nos atual, diante de inúmeros trabalhos que apontam este aspecto em seus resultados (Cordeiro, 2003; Gonçalves, 2008; Padilha, 2004; Pletsch \& Glat, 2011). A mesma observação aponta para questões implícitas: as condições historicamente constitutivas da educação destinada às massas no Brasil. A nossa história educacional tem muitos exemplos de descasos com a população brasileira e, mesmo nos momentos de avanços legais nesse campo, muitas vezes, como nos lembra Ianni (2002), os ideais humanísticos da cultura universal têm sido abandonados e os valores em pauta referem-se a "ideais pragmáticos, instrumentais, mercantis". A observação de Pacheco e Silva denuncia a falta de professores especializados diante de uma população específica (crianças internas em espaços segregados), mas não nos fornece pistas para falar das carências de professores na educação em geral. Diferentemente, hoje a presença de alunos com deficiências nas escolas comuns expõe alguns problemas: a qualidade de nossas escolas, a insuficiência na formação de nossos educadores, o baixo investimento, entre outros.

Tantos anos de exploração e descaso em relação à maior parte da população brasileira não deixam impunes nossas escolas, de modo que as características gerais da educação brasileira nos impedem de distinguir quais problemas escolares são decorrentes da especificidade dos alunos com deficiências, portanto, questões - de fato da educação especial, e quais seriam constitutivos da educação brasileira e que afetam todos os alunos.

A outra questão implícita também pode ser extraída do momento histórico em que tal observação foi registrada por Pacheco e Silva. Trata-se do fato de que aquelas crianças estavam internadas em um hospital psiquiátrico. Considerando a situação por este aspecto, identifica-se uma grande diferença de enfoque da questão: a legislação brasileira mudou radicalmente a abordagem do atendimento a essa população, inclusive tomando para si a responsabilidade de atendimento a esses alunos, pois a legislação atual privilegia o atendimento a alunos com deficiências nas escolas comuns públicas. Dessa forma, a incorporação e a efetivação dos direitos das pessoas com deficiências no país, seja por adesão a acordos internacionais, seja como decorrências de lutas internas de grupos organizados da sociedade civil brasileira, nos parecem um grande avanço.

No entanto, esse avanço ainda encontra limites. Como já exposto, serviços especializados são onerosos e, diante de restrições de investimento, são destinados à população brasileira programas de massa para uma escola com características precárias de funcionamento, onde condições de trabalho que resultem em aprendizado escolar 
pelos alunos nem sempre estão garantidas, apesar de cotidianos esforços de professores e alunos. Esse aspecto fica evidente na oferta de uma única forma de atendimento aos alunos com deficiências. Cabe lembrar que, ainda que a deficiência atinja todas as classes sociais, ${ }^{9}$ as consequências das políticas educacionais as impactam diferentemente, pois, enquanto os $20 \%$ mais ricos da população podem escolher usufruir ou não das ações em implantação de educação inclusiva na escola pública, a maior parte da população não tem tantas escolhas.

Com avanços e tropeços, a visão de marginalidade direcionada às crianças e jovens das camadas pobres brasileiras aos poucos vai perdendo força com a conquista de direitos, e a complexa relação do país com sua diversidade vai se desenrolando, no embate constante para a superação das desigualdades. Na escola, a luta pela efetivação de direitos esbarra na identificação das diferenças ainda como algo extraordinário e não como - de fato - constitutivas de nossa população.

\section{Notas}

1. Binet e Simon iniciaram seus trabalhos de mensuração da inteligência das crianças francesas matriculadas em suas escolas para o governo francês e, em 1905, publicaram uma escala de inteligência, cujo objetivo foi medir o desenvolvimento da inteligência das crianças de acordo com a idade (idade mental). Monarcha (2007) explica que, no Brasil, tal escala foi aplicada sob a orientação de Clemente Quaglio (1872-1948), na capital paulista.

2. Como exemplo, temos o Decreto-Lei n. 7.970-A, de 15 de outubro de 1927, do estado de Minas Gerais, que dispensava das aulas alunos mal vestidos e com incapacidades físicas e malformações. Já o Decreto n. 5.884, de 21 de abril de 1933, do estado de São Paulo, propunha a formação de escolas especiais para o grupo de anormais e, na impossibilidade disso, sugeria a formação de classes especiais.

3. Para mais detalhes, ver: <http://www.sagepub.com/upm-data/5901_Entries_Beginning_with_B_ Albrecht_Rev_I_Proof.pdf>

4. É interessante registrar que, no mesmo período, Erving Goffman publicou Manicômios, prisões e conventos, apresentando críticas fortes ao processo de institucionalização.

5. Nomenclatura utilizada à época.

6. A Declaração de Salamanca (1994) explicita essa preocupação. Sobre a relação custo-benefício na educação especial, ver Arruda, Kassar e Santos (2006).

7. Para detalhes de impactos da reforma do Estado na educação especial, ver Bueno e Kassar (2005), Kassar (2001) e Peroni (2011).

8. Dados relativos ao ano de 2008.

9. Ressalta-se que diferentes classes sociais registram diferentes índices de incidência de deficiências, devido, principalmente, ao acesso aos serviços de saúde (ver Jannuzzi \& Jannuzzi, 1998).

\section{Referências}

ALMEIDA, C.S. Análise dos motivos de encaminhamentos de alunos de classes comuns a classes especiais de escolas públicas de primeiro grau. 1984. Dissertação (Mestrado em Educação Especial) - Universidade Federal de São Carlos, São Carlos. 
ARRUDA, E.E.; KASSAR, M.C.M.; SANTOS, M.M. Educação especial: o custo do atendimento de uma pessoa com necessidades especiais em instituições pública estatal e não estatal, em MS, 2004. In: NERES, C.C.; LANCILLOTTI, S.S.P. (Org.). Educação especial em foco: questões contemporâneas. Campo Grande: Uniderp, 2006. p. 89-116.

BRASIL. Decreto n. 63.223, de 6 de setembro de 1968. Promulga a convenção relativa à luta contra a discriminação no campo do ensino. Diário Oficial da União, Brasília, DF, 10 set. 1968. Disponível em: <http://portal.mj.gov.br/sedh/ct/legis_intern/conv_ discriminacao_ensino.htm>. Acesso em: maio 2012.

BRASIL. Lei n. 4.024, de 20 de dezembro de 1961. Fixa as Diretrizes e Bases da Educação Nacional. Diário Oficial da União, Brasília, DF, 27 dez. 1961. Disponível em: <http://www.planalto.gov.br/ccivil_03/leis/L4024.htm>. Acesso em: abr. 2012.

BRASIL. Ministério da Educação. Plano Decenal de Educação para Todos. Brasília, DF: MEC, 1993. (versão atualizada). Disponível em: <http://www.dominiopublico.gov. br/download/texto/me001523.pdf>. Acesso em: abr. 2012.

BUENO, C.C.O.; KASSAR, M.C.M. Público e privado: a educação especial na dança das responsabilidades. In: ADRIÃO, T.; PERONI, V.M.V. (Org.). O público e o privado na educação: interfaces entre Estado e sociedade. São Paulo: Xamã, 2005. p. 116-135.

CARNEIRO JUNIOR, M. Educação das creanças anormaes. São Paulo: Siqueira Nagel, 1913.

COLLARES, C.A.L.; MOYSES, M.A.A. A transformação do espaço pedagógico em espaço clínico: a patologização da educação. São Paulo: FDE, 1994. (Idéias, 23). Disponível em: <http://www.crmariocovas.sp.gov.br/pdf/ideias_23_p025-031_c.pdf >. Acesso em: maio 2012.

CORDEIRO, C. A educação inclusiva na perspectiva dos professores: a ponta do iceberg. 2003. Tese (Doutorado em Educação) - Faculdade de Educação, Universidade de São Paulo, São Paulo.

DOWNING, J.E.; MACFARLAND, S. Education and individuals with severe disabilities: promising practices. In: INTERNATIONAL Encyclopedia of Rehabilitation. Buffalo: Center for International Rehabilitation Research Information and Exchange, 2010. Disponível em: <http://cirrie.buffalo.edu/encyclopedia/en/pdf/severe_disabilities_education_and_individuals_with_severe_disabilities_promising_practices.pdf $>$. Acesso em: abr. 2012.

FERREIRA, J. A exclusão da diferença. Piracicaba: Unimep, 1993.

FLYNN, R.J.; LEMAY, R.A. Introduction. In: FLYNN, R.J.; LEMAY, R.A. (Ed.). A quarter-century of normalization and social role valorization: evolution and impact. Ottawa: University of Ottawa, 2008. p. 3-13. 
GOMES, C.A.C. A democratização do ensino médio: ontem e hoje. Caderno SRH, Salvador, n. 34, p. 199-219, jan./jun. 2001. Disponível em: <http://www.cadernocrh. ufba.br/>. Acesso em: mar. 2012.

GOMES, M.R.L. Percepções: crianças negras e a patologização do fracasso escolar. In: SEMINÁRIO EDUCAÇÃO, Políticas educacionais: cenários e projetos sociais, 2009, Cuiabá. Anais... Cuiabá: UFMT, 2009. Disponível em: <http://www.ie.ufmt. br/semiedu2009/gts/gt15/ComunicacaoOral/MARCIA\%20REGINA\%20LUIZ\%20 GOMES.pdf $>$. Acesso em: maio 2012.

GONÇALVES, A.F.S. As políticas públicas e a formação continuada de professores na implementação da inclusão escolar no município de Cariacica. 2008. Tese (Doutorado em Educação) - Universidade Federal do Espírito Santo, Vitória.

HOBSBAWM, E.J. A era dos impérios. Rio de Janeiro: Paz \& Terra, 1989.

IANNI, O. O cidadão do mundo. In: LOMBARDI, J.C. et al. (Org.). Capitalismo, trabalho e educação. Campinas: Autores Associados; Histebr, 2002. p. 27-34.

JANNUZZI, G. A luta pela educação do deficiente mental no Brasil. São Paulo: Cortez; Campinas: Autores Associados, 1985.

JANNUZZI, G. A educação do deficiente no Brasil: dos primórdios ao início do século XXI. Campinas: Autores Associados, 2004.

JANNUZZI, G.; JANNUZZI, N. Incidência de deficientes no Brasil segundo senso demográfico de 1991: resultados empíricos e implicações para política. In: ENCONTRO NACIONAL DE ESTUDOS POPULACIONAIS, 11., 1998, Caxambú. Anais... Belo Horizonte: Abep, 1998.

JESUS, D.M.; VIEIRA, A.B. Políticas e práticas inclusivas no ensino fundamental: das implicações nacionais às locais. Educar em Revista, Curitiba, n. 41, p. 95-108, jul./set. 2011. Disponível em: <http://www.scielo.br/pdf/er/n41/07.pdf>. Acesso em: abr. 2012.

KASSAR, M.C.M. Reforma do Estado e educação especial: preliminares para uma análise. Revista de Educação, Campinas, v. 11, n. 1, p. 24-34, 2001.

KASSAR, M.C.M. Práticas pedagógicas e o acesso ao conhecimento: análises iniciais. In: MANZINI, E.J. (Org.). Inclusão e acessibilidade. Marília: ABPEE, 2006. v. 1, p. 79-86.

LIMA, L.C.A. Da universalização do ensino fundamental ao desafio de democratizar o ensino médio em 2016: o que evidenciam as estatísticas? Revista Brasileira de Estudos Pedagógicos, Brasília, DF, v. 92, n. 231, p. 268-284, maio/ago. 2011. Disponível em: <http://rbep.inep.gov.br/index.php/RBEP/article/viewFile/1806/1603>. Acesso em: abr. 2012. 
LIMA, L.G.; VENÂNCIO, R.P. Abandono de crianças negras do Rio de Janeiro. In: DEL PRIORI, M. (Org.). História da criança no Brasil. São Paulo: Contexto, 1991. p. 61-75.

LODOÑO, F.T. A origem do conceito Menor. In: DEL PRIORI, M. (Org.). História da criança no Brasil. São Paulo: Contexto, 1991. p. 129-145.

MANIFESTO dos Pioneiros da Educação Nova (1932). Revista do HISTEDBR On-line. Disponível em: <http://www.histedbr.fae.unicamp.br/revista/edicoes/22e/doc1_22e. pdf $>$. Acesso em: maio 2012.

MONARCHA, C. Sobre Clemente Quaglio (1872-1948): notas de pesquisa patrono da cadeira n. 31 "Clemente Quaglio". Boletim da Academia Paulista de Psicologia, São Paulo, v. 27, n. 2, p. 25-34, jul./dez. 2007. Disponível em: <http://redalyc.uaemex.mx/ redalyc/pdf/946/94627205.pdf>. Acesso em: mar. 2009.

NIRJE, B. How I came to formulate the normalization principle. In: FLYNN, R.J.; LEMAY, R.A. (Ed.). A quarter-century of normalization and social role valorization: evolution and impact. Ottawa: University of Ottawa, 2008. p. 17- 50.

PACHECO E SILVA, A.C. Carta a Norberto Sousa Pinto. In: PINTO, N.S. A infância retardatária: ensaios de orthophrenia. 2. ed. São Paulo: Escolas Profissionaes Salesianas, 1928.

PADILHA, A.M. O que fazer para não excluir Davi, Hilda, Diogo... In: GÓES, M.C.; LAPLANE, A.F. (Org.). Políticas e práticas de educação inclusiva. Campinas: Autores Associados, 2004. p. 93-120.

PASCHOALICK, W. Análise do processo de encaminhamento de crianças das classes especiais para deficientes mentais, desenvolvido nas escolas de $1^{\circ}$ grau da Delegacia de Ensino de Marília. 1981. Dissertação (Mestrado em Educação) - Pontifícia Universidade Católica de São Paulo, São Paulo.

PERONI, V.M.V. Público/privado na educação especial em tempos de redefinições do estado. In: KASSAR, M.C.M. (Org.). Diálogos com a diversidade: sentidos da inclusão. Campinas: Mercado de Letras, 2011. p. 39-60.

PINTO, J.M.R.; ALVES, T. Ampliação da obrigatoriedade na educação básica: como garantir o direito sem comprometer a qualidade? Retratos da Escola, Brasília, DF. v. 4, n. 7, p. 197-209, jul./dez. 2010. Disponível em: <http//www.esforce.org.br >. Acesso em: maio 2012.

PLETSCH, M.D. Repensando a inclusão escolar: diretrizes políticas, práticas curriculares e deficiência intelectual. Rio de Janeiro: Nau; Edur, 2010.

PLETSCH, M.D.; GLAT, R. A escolarização de alunos com deficiência intelectual em diferentes contextos educacionais. In: REUNIÃO ANUAL DA ANPEd, 34., 
2011, Natal. Anais... Natal: ANPEd, 2011. Disponível em: <http://34reuniao.anped. org.br/images/trabalhos/GT15/GT15-594\%20int.pdf>. Acesso em: maio 2012.

REBELO, A.S. Os impactos da politica de atendimento educacional especializado: análise dos indicadores educacionais de matrículas de alunos com deficiência. 2012. Dissertação (Mestrado em Educação Social) - Universidade Federal de Mato Grosso do Sul, Corumbá.

SÃO PAULO (Estado). Decreto n. 5.884, de 21 de abril de 1933. Institui o Código de Educação do estado de São Paulo. Diário Oficial do Estado, São Paulo, 10 maio 1933. Disponível em: <http://www.al.sp.gov.br/repositorio/legislacao/decreto/1933/decreto\%20 n.5.884,\%20de\%2021.04.1933.html>. Acesso em: jun. 2012.

SCHNEIDER, D. Alunos excepcionais: um estudo de caso de desvio. In: VELHO, G. Desvio e divergência. 2. ed. Rio de Janeiro: Zahar, 1977.

SILVA, G.B.; SCHELBAUER, A.R. Lourenço Filho e a alfabetização: os testes ABC e a reforma do sistema educacional no estado do Ceará. Revista do HISTEDBR online, Campinas, n. 25, p. 122-131, mar. 2007. Disponível em: <http://www.histedbr. fae.unicamp.br/revista/edicoes/25/art10_25.pdf >. Acesso em: abr. 2012.

WORLD HEALTH ORGANIZATION (WHO). World Report on Disability 2011. Genève: WHO; The World Bank, 2011. Disponível em: <http://whqlibdoc.who.int/publications/2011/ 9789240685215_eng.pdf>. Acesso em: maio 2012.

Recebido em 10 de junho de 2012.

Aprovado em 13 de julho de 2012. 